\title{
The EPR Spectra of Radical Ions Generated from Quinoxaline in Trifluoro- and Deuteriotrifluoroacetic Acid
}

\author{
JORMA ELORANTA and RAILI KOSKINEN
}

Department of Chemistry, University of Jyväskylä, Kyllinkatu 1-3, SF-40100 Jyväskylä 10, Finland

The triplet $(7.50 \mathrm{G})$ appearing in the EPR spectrum of the radical anion of dihydroquinoxaline in trifluoroacetic acid at room temperature is barely observable at $253 \mathrm{~K}$. In deuteriotrifluoroacetic acid, a quintet (1.18 G) appears in the EPR spectrum in place of the triplet. When quinoxaline was oxidized with thallium(III) trifluoroacetate at $253 \mathrm{~K}$, a radical was obtained, but it was destroyed when the temperature was raised.

In acidic solvents, nitrogen-containing aromatic molecules tend to attach a proton coordinately to the free electron pair on nitrogen.<smiles>c1ccc2c(c1)n1cnn21</smiles>

If two protons are attached to the radical anion of quinoxaline, denoted here $\mathbf{R}^{-}$, the radical ion $\mathrm{RH}_{2}{ }^{+}$is obtained. ${ }^{1}$ Since the $\pi$ electron structure of $\mathrm{RH}_{2}{ }^{+}+$is similar to that of $\mathrm{R}^{-}, \mathrm{RH}_{2}{ }^{+}$should be called the radical anion of dihydroquinoxaline (despite the positive charge).

The purpose of this work was the chemical assignment of the coupling constants of the protons attached to quinoxaline by comparing the EPR spectra obtained in trifluoroacetic and deuteriotrifluoroacetic acids. Decreasing the temperature affects the rate of the proton exchange reaction with the solvent and should be seen as line broadening in the EPR spectrum.

We also sought to prepare the cation radical of quinoxaline, using thallium(III) trifluoroacetate $^{2}$ as oxidizing agent.

Acta Chem. Scand. A 31 (1977) No. 7
Furthermore, we wished to compare the experimental coupling constants with the coupling constants obtained with INDO $^{3}$ and GEOMIN 4 calculations. (In the GEOMIN program the molecular geometry is optimized with respect to the total energy.)

\section{EXPERIMENTAL}

The samples were prepared in high vacuum and the ampoule used was made of quartz glass. ${ }^{5}$

Thallium(III) trifluoroacetate, trifluoroacetic acid and deuteriotrifluoroacetic acid were Merck products (for spectroscopy). Quinoxaline was a product of Fluka AG (laboratory grade) and was purified by gas chromatography.

The EPR spectra were recorded with Varian E-9 and E-12 spectrometers equipped with variable temperature controls and connected to Varian 620/L SS-100 computer facilities.

The spin density calculations and the simulations of the spectra were carried out on the UNIVAC 1108 central computer for Finnish universities.

Bond lengths according to Pople and Beveridge ${ }^{6}$ were used in the INDO calculations. They were also used as the initial data in optimizing the molecular geometry with the GEOMIN program.

\section{RESULTS AND DISCUSSION}

In Figs. 1, 2 and 3 we see the EPR spectrum of $\mathrm{RH}_{2}{ }^{+}+$in trifluoroacetic acid at room temperature and at $253 \mathrm{~K}$, respectively. The triplet caused by the protons in positions 1 and 4 $(7.50 \mathrm{G})$ appearing in the room temperature spectrum is broadened at the lower temperature. The quintet caused by the nitrogens (6.72 


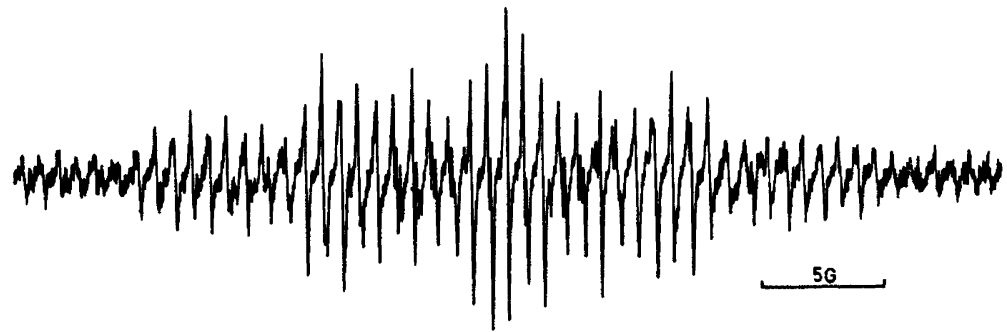

Fig. 1. The EPR spectrum of the radical anion of dihydroquinoxaline $\left(\mathrm{RH}_{\mathbf{2}}{ }^{+}\right)$in trifluoroacetic acid at room temperature.

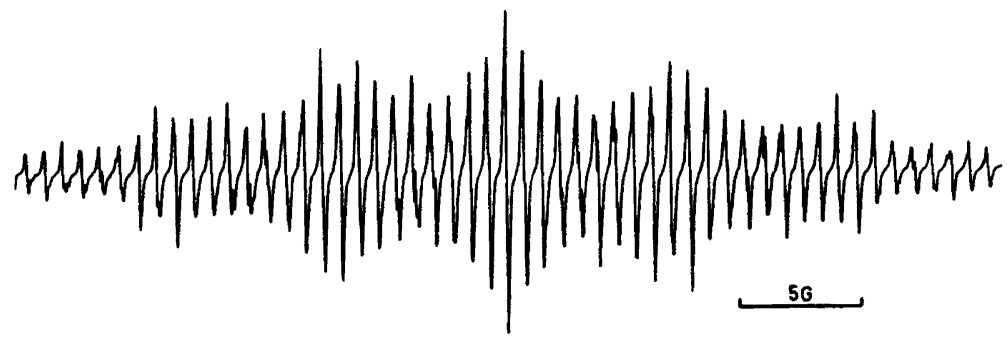

Fig. 2. The simulated EPR spectrum of the anion of Fig. 1 (based on Table 1 and the line width of $0.08 \mathrm{G}$ ).

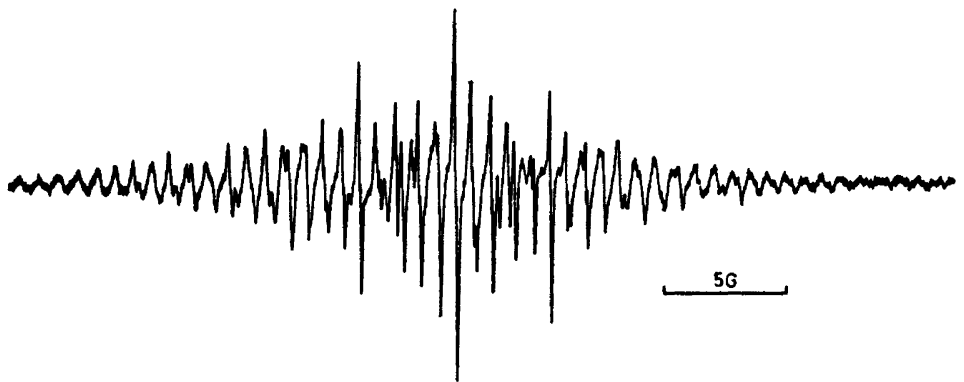

Fig. 3. The EPR spectrum of the radical anion of dihydroquinoxaline $\left(\mathrm{RH}_{2}{ }^{+}\right)$in trifluoroacetic acid at $253 \mathrm{~K}$.

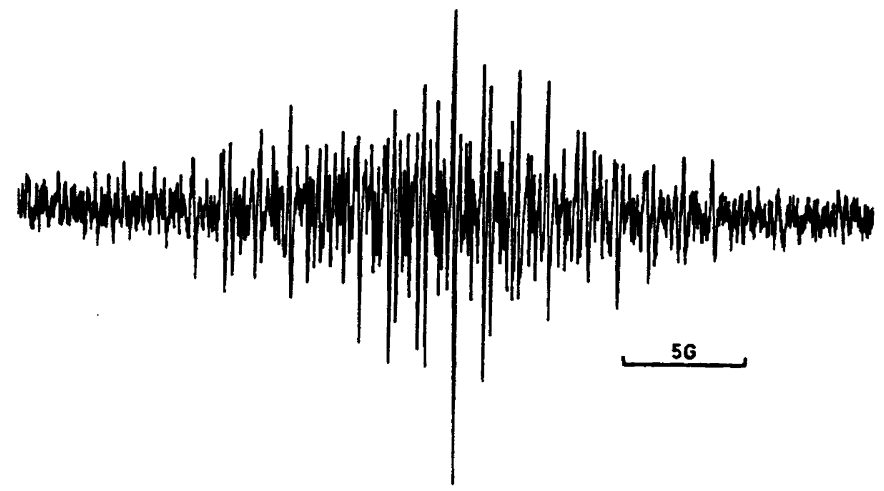

Fig. 4. The EPR spectrum of the radical anion of dideuterioquinoxaline $\left(\mathrm{RD}_{2}{ }^{+}\right)$in deuteriotrifluoroacetic acid at room temperature. 


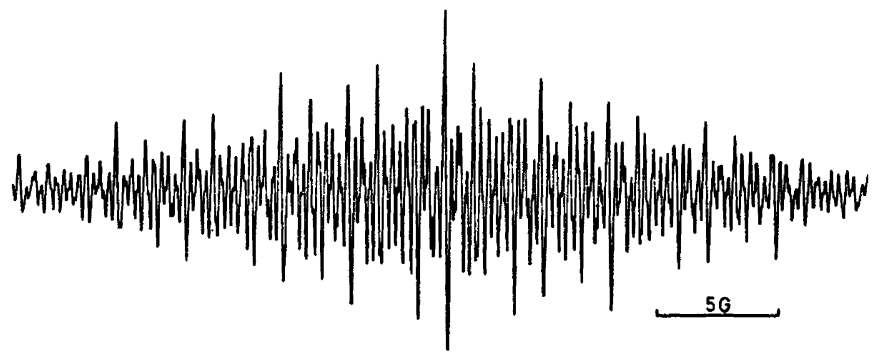

Fig. 5. The simulated EPR spectrum of the anion of Fig. 4 (based on Table 1 and the line width $0.08 \mathrm{G})$.

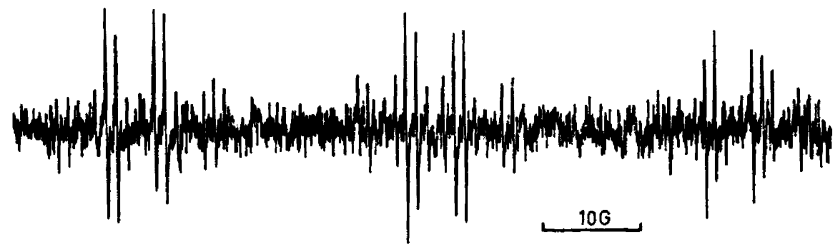

Fig. 6. The EPR spectrum of the radical ion generated from quinoxaline in trifluoroacetic acid with thallium(III) trifluoroacetate as oxidizing agent at $261 \mathrm{~K}$.

G) is also clearly broadened at the lower temperature. This line broadening is due to proton exchange reactions with the solvent. The other coupling constants are only slightly disturbed by proton exchange reactions. The rate of the reactions at room temperature is so high that the triplet appears with its normal intensity in the EPR spectrum.

When deuteriotrifluoroacetic acid is used as solvent (Figs. 4 and 5), the proton triplet of $7.50 \mathrm{G}$ does not appear in the EPR spectrum even at room temperature and a new quintet of 1.18 due to deuterium appears instead. Since $\mathrm{g}_{\mathrm{N}}(\mathrm{D}) / g_{\mathrm{N}}(\mathrm{H})=\mathbf{0 . 1 5 3 5}$, we can calculate' $a_{\mathrm{D}}=$ $0.1535 \times 7.50 \mathrm{G}=1.15 \mathrm{G}$, which is in good agreement with the experimental coupling constant.

No line broadening is observed in the EPR spectrum of the radical anion of dideuterioquinoxaline over the temperature range 253$300 \mathrm{~K}$.

Phenazine ${ }^{5}$ exhibits identical well-resolved EPR spectra in trifluoroacetic and trichloroacetic acids, whereas quinoxaline gives only a poorly resolved spectrum in the latter solvent. No EPR spectrum was obtained from quinoxaline in acetic acid. Attempts were made to prepare the cation radical of quinoxaline with thallium(III) trifluoroacetate in trifluoroacetic acid. The radical obtained was stable for only a few hours when the temperature was kept below $263 \mathrm{~K}$, and was destroyed when the temperature was raised.

The following coupling constants are observed in the EPR spectra of the radical (Figs. 6 and 7): one triplet $a(\mathrm{~N})=30.4 \mathrm{G}$ and two quartets $a(\mathrm{H})=4.9 \mathrm{G}$ and $a(\mathrm{H})=1.1 \mathrm{G}$. Neither a coupling of the other nitrogen nor of thallium $\left(I_{N}=1 / 2\right)$ is observed. If a complex of thallium and the radical cation of quinoxaline had formed, the $\pi$-electron structure of the radical ion would be different. The assignment of the coupling constant for the Tl-complex cannot be made with INDO calculations for orbital limitations. After the decomposition of the radical when the temperature increases, no

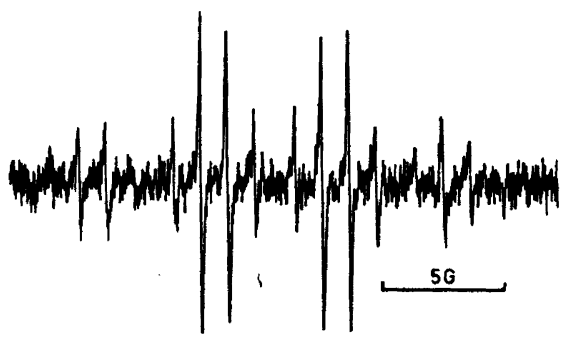

Fig. 7. Enlargement of the line group appearing in the middle of Fig. 6. 
Table 1. The coupling constants $(\mathrm{G})$ of the radical anions of dihydroquinoxaline and dideuterioquinoxaline.

\begin{tabular}{|c|c|c|c|c|c|}
\hline Position & $\begin{array}{l}\mathrm{RH}_{2} \cdot+ \\
\mathrm{CF}_{3} \mathrm{COOH} \\
\text { Room temp. }\end{array}$ & $253 \mathrm{~K}$ & INDO & GEOMIN & $\begin{array}{l}\mathrm{RD}_{2}{ }^{+} \\
\mathrm{CF}_{8} \mathrm{COOD} \\
\text { Room temp. }\end{array}$ \\
\hline $\begin{array}{l}1,4(\mathrm{~N}) \\
1,4(\mathrm{H}) \\
1,4(\mathrm{D}) \\
2,3 \\
5,8 \\
6,7 \\
\end{array}$ & $\begin{array}{l}6.72 \\
7.50 \\
- \\
3.80 \\
0.70 \\
1.48 \\
\end{array}$ & $\begin{array}{l}6.72 \\
- \\
- \\
3.85 \\
0.65 \\
1.48 \\
\end{array}$ & $\begin{array}{r}7.5 \\
-10.1 \\
=-2.3 \\
-0.5 \\
-0.7 \\
\end{array}$ & $\begin{aligned} & 7.7 \\
&- 11.1 \\
&- \\
&- 2.0 \\
&- 0.52 \\
&- 0.53 \\
&\end{aligned}$ & \begin{tabular}{l|}
6.68 \\
- \\
1.18 \\
3.93 \\
0.66 \\
1.46
\end{tabular} \\
\hline
\end{tabular}

Table 2. Bond lengths (nm) of the radical anion of dihydroquinoxaline as used with INDO and calculated with GEOMIN.

\begin{tabular}{lllllllll}
\hline & $1-2$ & $2-3$ & $1-9$ & $9-10$ & $5-10$ & $5-6$ & $6-7$ & $1(\mathrm{~N})-11(\mathrm{H})$ \\
INDO & 0.137 & 0.140 & 0.137 & 0.140 & 0.140 & 0.140 & 0.140 & 0.1015 \\
GEOMIN & 0.1369 & 0.1365 & 0.1399 & 0.1414 & 0.1405 & 0.1379 & 0.1399 & 0.10712 \\
\hline
\end{tabular}

radical anion of dihydroquinoxaline is formed.

INDO calculations with standard bond lengths ${ }^{\circ}$ gave the following order for the energies of the radicals: $\mathrm{RH}^{2}+>\mathrm{RH}^{\circ}>\mathrm{RH}_{2}{ }^{+}$. Thus, according to the calculations, $\mathrm{RH}_{\mathbf{9}}{ }^{+}+$has the most stable structure.

GEOMIN calculations lowered the total energy of the dihydroquinoxaline radical anion by about $25 \mathrm{~kJ} / \mathrm{mol}$ during the optimization of the bond lengths (Table 2), but the coupling constants were not better than the INDO values (Table 1).

\section{REFERENCES}

1. Barton, B. and Fraenkel, G. J. Chem. Phys. 41 (1964) 1455.

2. Elson, J. and Kochi, J. J. Am. Chem. Soc. 95 (1973) 5061.

3. Hase, H. and Schweig, A. QCPE Program 261 (1973).

4. Purcell, K. and Zapata, J. QCPE Program 312 (1976).

5. Eloranta, J., Paananen, I. and Koskinen, R. Acta Chem. Scand. A 31 (1977) 417.

6. Pople, J. and Beveridge, D. Approximate Molecular Orbital Theory, McGraw-Hill, New York 1970.

Received January 17, 1977. 